\title{
Addressing the Needs of Diverse Distributed Students
}

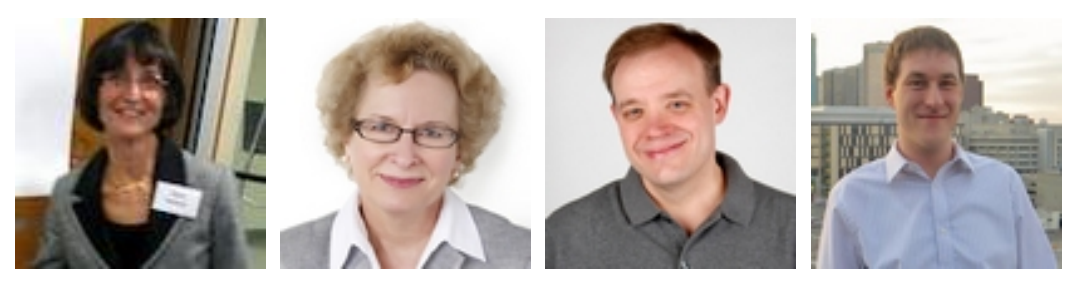

Rena Shimoni, Gail Barrington, Russ Wilde, and Scott Henwood Bow Valley College, Canada

\section{Abstract}

Two interrelated studies were undertaken to assist Alberta post-secondary institutions with meeting challenges associated with providing services to diverse distributed students that are of similar quality to services provided to traditional classroom students. The first study identified and assessed best practices in distributed learning; the second refined the focus to students who were identified as members of diverse subgroups. Research activities for the studies included: a comprehensive literature review of best practice in distributed service delivery; an online survey for students enrolled in distributed learning through eight colleges and technical institutes; staff and student focus groups; and interviews with students, front-line staff, senior post-secondary administrators, and representatives from provincial government and community organizations. Findings highlight impressions and experiences in relation to best practice criteria for service delivery in distributed learning, along with "best practices behind the best practices" that facilitate the adoption and improvement of distributed service delivery.

Keywords: Best practice; diversity; distributed learning; e-learning 


\section{Introduction}

The unprecedented numbers of students enrolling in courses and programs offered through alternative formats (Allen \& Seaman, 2009; Nagel, 2009; Radford, 2008), along with growing numbers of post-secondary institutions making the investment to expand their modes of content delivery (Parker, Lenhart, \& Moore, 2011), are gaining the attention of educators, policy makers, and researchers. Community colleges are on an upward trend in the number of courses and programs offered via distributed environments. Radford, for example, found that enrolment in post-secondary distance education ${ }^{1}$ was most common among students in two-year college programs. Similarly, Parker et al. revealed that $91 \%$ of two-year colleges in the United States offered online courses.

Though systematic e-learning enrolment data for Canada does not presently exist, it is estimated that between 875,000 and 950,000 students are now registered in a "purely online" college or university course at any one time, including approximately 100,000 full-time students (Contact North, 2012, p. 14). There is evidence Canadian policy makers see distributed learning becoming increasingly prevalent going forward (Borokhovski et al., 2011).

As distributed learning (defined here as any delivery mode available to students at a distance) has become more common, so too have examples of the successful use of distributed learning models. However, the mounting enthusiasm for distributed learning has been inconsistently matched in policy direction and in the use of best practices (Bates, 2011; Borokhovski et al., 2011; Contact North, 2012). The impact of this can be seen in institutions' organizational structure, staffing policies and procedures, and academic and other student related policies. While many examples of successful or best practice exist, they must be complemented by an understanding of how such practices relate to the experiences and needs of students who are diverse in their social, cultural, and English language backgrounds. Up to this point, there has been insufficient communication of issues and solutions in this area. While leaders in the post-secondary system seem committed to ensuring that distributed students receive instruction and services of a similar quality to their classroom counterparts, it is clear that more work is needed (Borokhovski et al., 2011). Canada is in need of system-wide solutions that help make distributed learning successful (Bates, 2011; Contact North, 2012).

Colleges in Alberta have a mandate to conduct applied research, undertaken to produce practical results with immediate application to real-world situations. In pursuit of this mandate, and in order to address gaps in knowledge to inform changes in policy and practice related to distributed learning, Bow Valley College (BVC) led two interrelated studies. The first, Successful Practices in Supporting Students in Distributed Learning

${ }^{1}$ The author cited the 2008 National Postsecondary Study Aid Study definition of a distance education class as "primarily delivered using live, interactive audio or videoconferencing, pre-recorded instructional videos, webcasts, CD-ROM, or DVD, or computer-based systems delivered over the Internet.” 
(Successful Practices), explored best practices in distributed student support as well as the cultural, structural, and policy features of organizational practice that make these practices possible - the 'best practices behind the best practices' (Shimoni, Barrington, \& Wilde, 2010). The second study, Meeting the Needs of Diverse Students Engaging in e-Learning (Diverse Students), examined the needs of diverse students in a distributed learning environment and the extent to which needs were being or could be met (Shimoni \& Barrington, 2010). The first study was funded by the Alberta Ministry of Advanced Education and Technology (AET); the second received funding from eCampusAlberta, a consortium of Alberta post-secondary institutions established to facilitate access to online learning.

Both studies examined existing successful practices in distributed learning, and were conducted simultaneously in partnership with eight Alberta colleges and technical institutes: BVC, Lethbridge College, Northern Alberta Institute of Technology, NorQuest College, Northern Lakes College, Olds College, Portage College, and Red Deer College. The studies were guided by a single steering committee comprised of senior representatives from the eight partner organizations, the director of eCampusAlberta, and a representative from AET.

While there is overlap in the interests of the two studies, they are distinctive in both primary focus and research questions. The first study sought to uncover best practices in supporting the general distributed student population. The second refined the focus to specific sub-groups of students who may have had needs distinctive from, or in addition to, those of the general student population. As many of the participants were from the same populations, the data collection tools for both studies were combined, allowing researchers to be more effective in data collection and more respectful of the time commitment of participants. Presenting the findings of the studies together allowed key stakeholders to obtain a broader view of both problems and proposed solutions, and ensured that the needs of the populations studied in the Diverse Students study would be integrated into recommended policy and practice.

\section{Study Goals and Key Research Questions}

One purpose of the Successful Practices study was to explore the current state of academic, enrolment, and student services across publicly funded colleges and technical institutes in Alberta as well as in the community organizations that support adult learners. This involved the identification of services and strategies that contributed to the success and satisfaction of distributed students, along with areas requiring change. Institutional policies, procedures, and practices that were seen as essential for the implementation of successful practices were reviewed.

The Diverse Students study examined the existing services and the need for further or different supports for diverse students. The term diverse was broadly defined purposely so - and identified sub-groups included students residing in rural areas, nonnative English speakers, Aboriginals, and those with disabilities (including learning or 
physical disabilities and mental health concerns). It was presumed that such students may have need for services and/or strategies different than, or in addition to, those identified in the Successful Practices study.

The intention of both projects was to develop recommendations that would lead to higher quality support services for distributed students. The studies sought both to develop a greater understanding of successful practices and needs of diverse students within a distributed learning environment, and to inform the successful implementation of practices and policies to help post-secondary institutions better serve their distributed students. Project funding included the production and implementation of tools and processes for disseminating findings and acting on steering committee recommendations. These processes are ongoing and will be reported on separately.

Key research questions of the two studies addressed students, college services, and the post-secondary system and are presented in Table 1.

Table 1

Research Questions by Study

Study Research questions

Successful Practices in Supporting Students in Distributed Learning

Meeting the Needs of Diverse Students Engaging in eLearning
- What are the existing best practices in innovative alternative service delivery to students?

- What are the "best practices behind the best practices" - the cultural, administrative, human resource, and policy supports within postsecondary institutions that are congruent with successful alternative delivery programs?

- What are effective strategies to encourage collaboration and information sharing among post-secondary institutions?

- What changes are required for post-secondary institutions desiring to implement relevant and efficient academic learning services to distributed students?

- What are needs of diverse groups within the overall student population as it pertains to distributed learning?

- What barriers currently prevent participation? What would reduce these barriers?

- What successes or promising practices exist that have demonstrated effective support for diverse students?

- What inter- and intra-institutional changes are required to provide required services to diverse distributed students? 


\section{Methods and Tools}

The following section describes the research activities undertaken for the two studies, including a description of the relevant populations targeted.

\section{Literature Review}

A review of relevant studies in online and other non-traditional learning environments was carried out prior to the two studies (Fiege, 2010). The review served as background for the research in developing a conceptual framework and fostering shared understanding of a "best practice" for distributed learning. Current literature and the field-based experience of the steering committee led to the development of a definition of a "best, successful, or promising practice" as any practice that reduced or eliminated barriers to students' access to services and academic success.

In addition to the online provision of services, which much of the existing research considers an essential component of best practice (see LaPadula, 2003; McCracken, 2005), these studies included other delivery modes provided they were available to students at a distance and at times that were convenient to them, such as blended approaches, video- and teleconferencing, and itinerant trainers. This definition of distributed learning allowed the research team to simultaneously categorize environments outside of traditional classroom learning and address challenges associated with definitions in this domain (Canadian Council on Learning, 2009; Moore, Dickson-Deane, \& Galyen, 2011).

The literature review examined available knowledge, largely through peer-reviewed journals and books, on best practice in distributed learning, along with its applicability to the needs of diverse students ${ }^{2}$. The review organized available evidence according to the inclusive student services process model proposed by Floyd and Casey-Powell (2004), which provides a "framework for designing processes and programs to support students in both traditional and online courses" (as cited in Fiege, 2010, p.17). Based on findings from the literature review, a list of 10 criteria for successful practice in serving diverse distributed learners was developed. These criteria were vetted by members of the steering committee who had extensive experience in the implementation of distributed learning in their respective institutions. After incorporating feedback from the steering committee, the best practice criteria were finalized, forming the basis of subsequent elements of the studies:

1. The admissions and registration processes are well-organized and easy to follow.

2. Students can access comprehensive initial assessment, academic advising, and orientation.

\footnotetext{
2 The literature review can be accessed through the eCampusAlberta website: http://www.ecampusalberta.ca/files/Literature_Review_Report.pdf
} 
3. Financial aid and financial services information are provided to students on the institution's Web site.

4. Students can access adequate support on how to use and troubleshoot technology.

5. Students can access adequate academic and/or tutorial support services, including assistance with learning strategies and writing skills.

6. Students can access bookstore services and relevant bookstore information.

7. Students can access library services and relevant library information.

8. Students can access adequate career counselling and relevant career services.

9. Students can access adequate personal counselling and relevant counselling services.

10. Students in identified diverse subgroups (Aboriginals, non-native English speakers, rural students, and those with disabilities or mental health issues) can access adequate support services.

\section{Participants}

The studies elicited participation from individuals connected with distributed learning through a variety of perspectives. Participants included key informants from colleges, technical institutes, community organizations, and provincial government.

Post-secondary representatives included senior administrators, deans, and directors involved in decision-making for distributed learning at the partner institutions. In addition, front-line staff from these institutions took part in the research, including representatives from each of the best practice service areas identified from the literature review. Community organizations whose members provided input were the Community Adult Learning Centres of Alberta (CALC) and Innovative Communities Connecting \& Networking (ICCAN). Representatives from two provincial government ministries Alberta Advanced Education and Technology and Alberta Employment and Immigration - also participated.

A significant portion of the research involved contributions from students engaged in distributed learning through the 16 eCampusAlberta member institutions. Students were considered as both an overall group and by identified sub-groups of diverse students, including Aboriginal students, students with disabilities or mental health issues, new Canadians for whom English is a second language, and rural students. 


\section{Data Collection Methods and Tools}

A variety of data collection tools were employed for the two studies. An online survey was deployed to address the 10 best practice criteria identified by the literature review as well as to identify members of identified diverse sub-groups. Survey data was used as a means of informing a subsequent qualitative component of the studies, involving interviews and focus groups.

Originally, focus groups were planned for front-line staff and students for the Successful Practices study, primarily based on resource considerations. With the subsequent funding of the Diverse Students study, interviews were added to ensure that input from these students (including those with disabilities and non-native English speakers) was appropriately represented. Ultimately, practical considerations determined whether focus groups or interviews were used. For example, it was at times impossible to coordinate participant schedules for a focus group discussion, in which case researchers attempted to reach individuals for an interview to ensure representation from all partner institutions.

While each project had its own logic model and data collection matrix (DCM), most target populations were the same. As such, data collection tools were largely designed with integrated questions for both studies to avoid placing additional demands on the time of participants ${ }^{3}$. See Table 2 for participant totals for each data collection method.

\section{Survey.}

An online survey was targeted exclusively at students enrolled in programs using distributed learning environments at each of the eight partner institutions. Prior to its launch, the survey was piloted with a group of students at BVC, after which minor revisions were made. The survey was also reviewed by an expert in English language learning to determine whether the language used was appropriate for all student participants.

The survey included measures for helpfulness of services for distributed students, including English support, intake processes, orientation, academic advising, textbook services, library services, technical support, instructor support, career services, and more (Shimoni, Barrington, \& Wilde, 2010). Tests for Cronbach's alpha indicate that responses to items measuring these concepts are consistent, with all measures producing scores above 0.7 (alpha was not calculated for measures with fewer than three items). Students were also encouraged to provide more information through openended comment boxes.

All students enrolled in courses at each of the partner institutions with access to their institution's learning management system (LMS) were recruited to participate in the

\footnotetext{
${ }^{3}$ Copies of the data collection tools can be found as appendices to the final study reports, hyperlinks to which are available in the reference list.
} 
survey. Students were recruited through LMS administrators, who posted the hyperlink for the survey in three ways: 1) emailed to students; 2) posted to the login page of their LMS; or 3) posted to the announcements page of their LMS. The survey was also posted to the homepage of the eCampusAlberta Web site. Respondents were free to self-select to complete the survey, and it is possible that some were enrolled in both distributed and traditional face-to-face courses at the time of completing the survey.

As an incentive for participation, students were given opportunity to enter a draw for a portable media player. The survey controlled for students who were not enrolled in an online course or program through a screening question at the beginning of the survey; these respondents were still permitted to enter the draw. The survey was administered using Fluid Surveys ${ }^{4}$ and was live for six weeks.

\section{Interviews.}

Open-ended interview protocols were developed and used with students, front-line staff, senior college administrators, and representatives from community organizations and provincial government departments. As a validation measure, all interview protocols were reviewed by the steering committee, who provided feedback on wording and relevance of the questions as well as their views of the completeness of the tools.

Students were recruited for interviews through an item in the online survey. Steering committee members identified and provided contact information for administrators and front-line staff at the partner colleges, as well as for relevant government officials. Representatives for community organizations were contacted directly by the researchers. Additional interview participants were recruited through existing participants using a common "snowball" recruitment technique (Goodman, 1961). Students were asked about their experience with college services from a distributed learning perspective. Questions also focused on student perceptions regarding what was needed for them to be successful in their course or program. Other participants were asked questions on similar topics as relevant to their respective roles.

\section{Focus groups.}

Focus groups were conducted with students and front-line staff. Similar to the process undertaken to construct the interview tools, the focus group protocols were reviewed by the steering committee for wording, relevance, and completeness. Using the snowball technique, staff participants were identified by steering committee members and they in turn recommended other participants. Similar to interview recruitment, students who indicated interest in a focus group through the online survey were invited to participate. Topics discussed by focus groups were also similar to those covered in interviews.

\footnotetext{
${ }^{4}$ See http://fluidsurveys.com/
} 
In light of the distributed learning focus of the studies, focus groups were facilitated through Adobe Connect 5 , a web-based interactive communication tool with two-way audio and instant messaging capabilities. In cases where technical difficulties prevented a participant from taking part in a focus group, attempts were made to follow up for an interview instead.

\section{Policy review.}

An attempt was made to examine government and college policies to see how they informed, supported, and/ or unintentionally discouraged ${ }^{6}$ best practices for diverse distributed students. The Government of Alberta policy regarding educational institutions providing online/distance education served as background for the studies. An initial web-based search for relevant policy documents from partner colleges was conducted, as well as a further online search among several institutions recognized for their success in distance education. Additionally, a request was made by BVC's vicepresident learning to all institutions that were members of the Alberta Association of Colleges and Technical Institutes (AACTI) requesting they share any policies that may not have been accessible online. Finally, if policies were mentioned by a study participant as part of an interview or focus group, an attempt was made to follow up and obtain a copy.

\section{Data Analysis}

\section{Quantitative analysis.}

Responses from the student survey were downloaded and analyzed using traditional techniques for descriptive statistics. An emergent analysis framework was developed to look at services from the perspective of

- availability,

- participation or use,

- ease or difficulty, and

- utility.

Information was organized by college and sub-group according to the general topics in the DCM. Using SPSS, frequencies and percentages were calculated and scale items were analyzed for means and standard deviations. In some cases, cross-tabulation analysis was also conducted. Open-ended items were examined through the development of emergent categories and the information was coded, sorted, and summarized.

\footnotetext{
${ }^{5}$ See http://www.adobe.com/products/adobeconnect.html

${ }^{6}$ For example, attendance-based student funding could unintentionally exclude distributed learners from eligibility.
} 


\section{Qualitative analysis.}

Thematic analysis was performed on data from interviews and focus groups. Transcriptions were entered into a word processor and were then transferred into a spreadsheet and coded for themes based on relevant questions in the DCM. Sub-themes were identified and coded as they emerged. Coded comments were organized by research question and participant group and were then sorted by frequency and key themes according to each best practice category identified in the literature as well as according to relevant sub-group. An 11th category was developed to capture the best practices behind the best practices. Representative quotes were selected for inclusion in the final reports, some of which have been carried over to this article.

\section{Policy analysis.}

The review yielded few examples of policies in place at post-secondary institutions related to distributed students. If policies existed, they were not publicly available through institutions' Web sites or calendars. In addition, requests to institutions for policy samples were either not returned or received a response that the institution had not yet adopted policies specific to distributed learning. Some institutions reported they were in the planning stages of developing policies in this domain. Ultimately, only one institution responded with an example of an adopted and implemented distributed learning policy. As a result, the decision was made to forego policy analysis for these studies and to pursue this area of inquiry at a later time.

\section{Data Summary}

A comprehensive data summary was compiled and reviewed by the research team. In addition to considering the triangulation of data, summarized data was compared with observations from the field. From there, best practice data were analyzed according to criteria determined from the literature review and assessed for cross-college applicability. Finally, draft study conclusions and recommendations for the two studies were developed for review by the steering committee.

\section{Results and Discussion}

Findings from the two studies are summarized below. Integrated conclusions, recommendations, and next steps stemming from study findings are described in the sections that follow.

\section{Participation}

Of over one thousand total participants, 942 were students enrolled in courses offered via distributed learning. An additional 112 participants were post-secondary staff, 
administrators, and representatives from government and community organizations. The breakdown of participants is presented in Table 2.

Table 2

Study Participants by Data Collection Tool

\begin{tabular}{|l|c|}
\hline \multicolumn{1}{|c|}{ Data collection tool } & $\begin{array}{c}\text { \# of } \\
\text { participants }\end{array}$ \\
\hline Student survey & 942 \\
\hline Student interviews & 34 \\
\hline Student focus groups & 5 \\
\hline Front-line staff interviews & 36 \\
\hline Staff focus groups & 21 \\
\hline College administrator interviews & 42 \\
\hline Government personnel interviews & 4 \\
\hline CALC/ ICCAN interviews & 9 \\
\hline
\end{tabular}

\section{Successful Practices in Distributed Learning}

Findings from the Successful Practices study are organized according to each of the 10 best practice criteria that emerged from the literature review and were validated by the steering committee. The key organizational policies, strategies, and structures required to sustain these practices are also summarized.

\section{Best practices.}

\section{The admissions and registration processes are well-organized and easy to follow.}

The first issue I had was when I was actually researching to join this program. I emailed a few times to the school just to get an idea of what was required and that type of thing ... And what I found was that the program coordinator ... didn't respond to me for two or three days at a time and she also didn't take the time to discuss my options. I've been out of school for seven years and I had no idea how this practice works. (Student) 
Students and staff alike acknowledged the importance of being able to access information online prior to and during the admission and registration process. Students also identified the need for an accessible and knowledgeable contact person to assist them with this process.

\section{Students can access comprehensive initial assessment, academic advising, and orientation.}

Student experience with these processes was limited: Twenty-two percent of survey respondents ( $\mathrm{n}=717$ ) reported having undergone an initial assessment, 40\% had spoken with an academic advisor $(\mathrm{n}=712)$, and $35 \%$ had participated in an orientation session ( $n=706$ ). This suggests that either these services were not widely available at the partner colleges at the time of research or that students were often not aware of their existence or potential to assist.

\section{Financial aid and financial services information are provided to students on the institution's Web site.}

Students indicated that they needed more information on financial aid. However, other stakeholders suggested this lack of information is related to limited funding options for part-time online students, putting many students at a disadvantage. Funding tends to be tied to the number of credits taken by students, their level of involvement (i.e., part-time or full-time), and the nature of program delivery (i.e., asynchronous or synchronous).

Because [my program] is online I don't qualify for anything. You have to actually attend the class in order to get any of the funding. (Student)

\section{Students can access adequate support on how to use and troubleshoot technology.}

I took an online course because I work full-time. The only time I have time to work on my studies is on the weekend, when tech support is closed. (Student)

Respondents from all groups recognized the importance of readily available technical support for students 24 hours a day (or at least extended hours). Quick response times from help desk staff or others providing assistance, and access to up-to-date and compatible technology, were also identified as essential services.

\section{Students can access adequate academic and/or tutorial support services, including assistance with learning strategies and writing skills.}

While access to academic support services is necessary, the role of instructors was seen as much more critical for distributed students. Students identified a number of unmet needs related to course design, including the need for greater interaction with both 
instructors and peers to accommodate various learning styles, to model the learning expected of them, and to include opportunities for discussion. Students' schedules were another identified barrier as they related to scheduling course exams. Participants suggested that the use of blended delivery models and universal design principles would support greater accessibility of course materials. Instructor training regarding the needs of distributed students remained central to these participants, some of whom felt their needs were not prioritized appropriately:

[O]ne of my biggest issues with online learning is that the instructor often has a lot on their plates or they don't realize what online teaching entails and they tend to put us on the back burner, or that is how it seems. You might not get feedback, for example on a posting or what-haveyou, for a month or two months. You might not know until after the mid-term whether your group is on the right track or if you are way off in left field. (Student)

\section{Students can access bookstore services and relevant bookstore information.}

An issue raised by students was their need to order books online. Access to bookstore services during extended hours and access to booklists prior to course start dates were also identified as important.

\section{Students can access library services and relevant library information.}

Students indicated that navigation of library Web sites was a barrier, particularly when trying to find required materials (e.g., journal articles). Best practice for library assistance noted by both students and staff was orientations and/ or tutorials for online library services, as well as the availability of real-time support provided through an instant messaging service on the library's Web site or through a help line:

Yeah I use the online (library). It works really well ... One thing that is offered to us in online courses is there has been a person to call that is going to help you for that course who works at the library. If you can't find something in the database you can always call and get help ... I wish it was 24 hours but it's not. (Student)

\section{Students can access adequate career counselling and relevant career services.}

Few students (7.5\% of 691 respondents) reported that they had accessed career counselling services. This finding reinforces comments made by front-line staff and 
senior administrators that there was a need to find better ways to provide and engage distributed students in these supports.

\section{Students can access adequate personal counselling and relevant counselling services.}

Five percent of students $(n=638)$ had accessed counselling services, and of these only one student reported having accessed these services online. In many cases, these services may not have been available to off-site students. A key challenge identified by staff was the fact that many online students do not disclose their personal and/or learning needs, making early identification difficult. Lack of face-to-face interaction was also reported to prevent instructors or other advisors from noticing signs that may indicate a student requires counselling services.

\section{Diverse students can access adequate support services}

On the whole, participants identified as "diverse students" either faced challenges in accessing relevant support services, or were unaware that services existed7.

\section{Best practices behind the best practices.}

\section{Paradigm shift}

A need was identified for a paradigm shift in the post-secondary system to incorporate a full commitment to distributed learning, as opposed to the view of alternative delivery as an add-on to routine practice.

\section{Quality assurance policies}

Senior college personnel identified a lack of policy related to quality assurance and ways to measure distributed learning, and demonstrated uneven awareness regarding existing policies.

\section{Training and support for instructors}

Instructors play a key role in the provision of quality distributed learning. However, training and support to orient instructors to students' learning needs in a distributed environment and to the appropriate technology for online teaching were described as limited.

\section{Institutional collaboration}

Participants identified a strong need for coordination and collaboration, both within and between institutions. Colleges need to share information about distributed learning across departments and systems. Additionally, systems to facilitate cross-college

\footnotetext{
${ }^{7}$ This point is expanded upon in the report of findings from the Diverse Students study.
} 
enrolment and college-community partnerships and resources are needed to support rural students.

\section{Greater options for funding}

Financial support for distributed learning was described as limited for both students and institutions, and this was identified as a barrier to effective delivery and student participation.

\section{Needs of Diverse Students in Distributed Learning}

Findings from the Diverse Students study relate to both the needs of identified subgroups and relationships between these needs and the identified best practice criteria. Of the 942 survey respondents, 32\% identified themselves as rural students, $15 \%$ as non-native English speakers (NNES), 9\% as Aboriginal students (First Nations, Métis, or Inuit), and $6 \%$ as having a disability or mental health concern. Figures for survey respondents who self-identified as part of each of these sub-groups are presented in Table 3, sorted by institution.

Table 3

Diverse Learners by Sub-Group and Institution

\begin{tabular}{|l|c|c|c|c|c|c|c|c|}
\hline \multirow{2}{*}{ Institution } & \multicolumn{2}{|c|}{$\begin{array}{c}\text { Students with } \\
\text { disabilities }\end{array}$} & \multicolumn{2}{c|}{ NNES students } & \multicolumn{2}{c|}{$\begin{array}{c}\text { Aboriginal } \\
\text { students }\end{array}$} & \multicolumn{2}{c|}{ Rural students } \\
\cline { 2 - 9 } & $\mathrm{n}$ & $\%$ & $\mathrm{n}$ & $\%$ & $\mathrm{n}$ & $\%$ & $\mathrm{n}$ & $\%$ \\
\hline $\begin{array}{l}\text { Bow Valley } \\
\text { College }\end{array}$ & 14 & 30.4 & 54 & 46.6 & 8 & 11.8 & 50 & 20.8 \\
\hline $\begin{array}{l}\text { Lethbridge } \\
\text { College }\end{array}$ & 3 & 6.5 & 1 & 0.9 & 9 & 13.2 & 20 & 8.3 \\
\hline NAIT & 9 & 19.6 & 46 & 39.7 & 10 & 14.7 & 44 & 18.3 \\
\hline $\begin{array}{l}\text { NorQuest } \\
\text { College }\end{array}$ & 2 & 4.3 & 6 & 5.2 & 9 & 13.2 & 21 & 8.8 \\
\hline $\begin{array}{l}\text { Northern } \\
\text { Lakes } \\
\text { College }\end{array}$ & 0 & 0.0 & 0 & 0.0 & 0 & 0.0 & 2 & 0.8 \\
\hline $\begin{array}{l}\text { Olds } \\
\text { College }\end{array}$ & 2 & 4.3 & 1 & 0.9 & 0 & 0.0 & 4 & 1.7 \\
\hline $\begin{array}{l}\text { Portage } \\
\text { College }\end{array}$ & 7 & 15.2 & 3 & 2.6 & 28 & 41.2 & 63 & 26.3 \\
\hline $\begin{array}{l}\text { Red Deer } \\
\text { College }\end{array}$ & 9 & 19.6 & 5 & 4.3 & 4 & 5.9 & 36 & 15.0 \\
\hline Total & $\mathbf{4 6}$ & $\mathbf{1 0 0 . 0}$ & $\mathbf{1 1 6}$ & $\mathbf{1 0 0 . 0}$ & $\mathbf{6 8}$ & $\mathbf{1 0 0 . 0}$ & $\mathbf{2 4 0}$ & $\mathbf{1 0 0 . 0}$ \\
\hline
\end{tabular}


In addition to students, other study participants who had experience with diverse distributed students contributed to the identification of key barriers and supports. These findings are organized according to common themes.

\section{Shared needs}

Overall, diverse students reported many of the same needs as the general student population participating in distributed learning. The provision of online supports - such as orientation, library support, and technical assistance - was identified as important by many students regardless of demographic. As in the Successful Practices study, participants indicated that such supports were inconsistently available to and accessed by distributed students. In addition, there were few unique needs identified for each sub-group. Most needs were shared by two or more sub-groups, though these needs may have been experienced in different ways and necessitate different strategies for resolution.

\section{Blended delivery methods}

I think the other thing too is, with our learners, it needs to be engaging. It just can't be your face-to-face course but online with just a bunch of text. There are a lot of learners who do use a lot of technology and they are used to Facebook and Skype and all of those things and I think their expectation would be more dynamic, not just all word documents, and it builds a sense of community. (College front-line staff member)

Comments from all participant groups, and all student sub-groups, expressed the desire for greater interaction with instructors and classmates. Greater face-to-face communication (e.g., through video-conferencing) was found to help address the sense of isolation reported by rural and Aboriginal students as well as those with disabilities. Opportunities for verbal interaction were reported to support the oral traditions and learning styles common within Aboriginal cultures. Verbal and face-to-face interaction was also reported to support the learning of non-native English speakers.

\section{Access to technology}

Learners outside of [community name] do not have sufficient access to computers or internet. Many learners have no access to high speed internet in their homes. Many small communities have no high speed internet... (There are) few computers and no video conference equipment. (Community organization member)

A key barrier to successful participation in distributed learning for rural students and Aboriginal students (many of whom reside in rural communities) was access to essential 
resources. These included stable internet connections as well as software applications needed for full participation in their courses. Lack of transportation also played a role in access issues.

\section{Community organizations}

Community organizations were identified as a resource to connect students with necessary technology and technical support. The fact that use of these organizations was noted as best practice both by their representatives and by government officials but were seldom mentioned by front-line staff and senior administrators suggests that they are an underused resource.

\section{Early identification of student needs}

Students' responses varied as to whether they underwent a needs assessment at the outset of their programs. As such, challenges related to English language ability, learning disabilities, physical disabilities, and mental health concerns were inconsistently identified - all with consequences for the provision of supports. College personnel reported that many distributed students in need of language assistance, counseling, or other specialized supports did not self-disclose. This increased the challenge of providing needed services in a timely fashion. For those who had selfdisclosed, accessibility of services remained an obstacle to receiving assistance:

I think the biggest barrier for a lot of our students is that lack of supportive services, especially some of our students with learning disabilities or students with mental health issues. Being isolated is a huge barrier for them. I know online isn't the ideal place for a person to get a lot of collaboration and support and I think there are more things we can do in providing those supports. That sense of being a part of a class and part of a bigger environment. (College front-line staff member)

\section{Universal design}

The theme of universal design (the design of products, resources, and services for use by people with a wide range of abilities and circumstances) in the creation and delivery of course content was raised by college personnel and students, and was related to needs of students with disabilities and non-native English speakers.

In terms of students with disabilities we ensure that all of our video streaming has closed captions. We design our sites for universal design. We cut them to make sure if you are colour blind it is going to look a certain way. We take advice from our centre for learning support 
when we are designing these sites. (College front-line staff member)

For those with disabilities, access to adaptive or assistive technology was identified as a key support; however, access to such technology at home and support in using the technology were identified as challenges. The use of plain and consistent language in course delivery was viewed as a vital support for non-native English speakers (and all distributed students in general). Participants also pointed out that differences between spoken language and language typically used online could pose a challenge for students still learning English.

\section{Funding}

Lack of or insufficient funding was frequently seen as a barrier for distributed students. In particular, the availability of funding for rural, part-time, asynchronous distributed students was reportedly limited in comparison with urban, full-time, and traditional classroom students. Funding for community groups to purchase current technology that could benefit rural and other distributed students was also reported to be difficult to obtain.

\section{Key Findings}

The examination of findings brings the extensive connections between the two studies into focus. Figure 1 demonstrates the findings of the studies, with conclusions from Title1 on the left, Title2 on the right, and common findings in between. 
Solutions to many of the problems experienced by distributed students already exist - separately and individually within partner institutions - and need to be shared.

Policies on all aspects of distributed learning are unevenly distributed in Alberta's post-secondary institutions.

Communication systems and processes for online services should be standardized, accessible, sequential, and timesensitive.

Within institutions, communication and collaboration about the needs of distributed students must occur across services and departments.

\section{Common Findings}

What is good for diverse students is good for all students.

Instructors are the face of the institution for distributed students, and play a critical role in connecting students to services.

Community agencies are a major untapped resource that should be a gateway for distributed students.

Funding practices appear to be a barrier to both distributed students and the organizations that serve them.
Organizations must find ways of encouraging selfdisclosure for students who may require special assistance due to language or other challenges.

Blended methods of delivery were seen as most desirable for diverse students.

The use of universal design principles make distributed delivery more accessible for diverse students.

Opportunities for verbal communication and face-to-face interaction support non-native English speakers and are sensitive to cultural expectations of Aboriginal students.

Figure 1. Key findings of the studies. 


\section{Strengths and Limitations of the Studies}

Due to privacy concerns, a Canadian software company, FluidSurveys, was chosen to collect data for the survey. There were some glitches in this system that resulted in loss of data, and unreliable data was not included in the analysis. Specifically, there was a need to eliminate age from demographic descriptions of students.

Some data was lost due to technical difficulties in the taping of telephone interviews. Similarly, researchers and participants experienced connectivity and hardware issues during the focus groups, including computer issues, microphone failures, and headset problems. As well, despite orientation and back-up support, some respondents did not have the technological experience necessary to participate successfully.

While a considerable number of students took part in the studies overall, students with disabilities and Aboriginal students were few in number. Therefore, it is difficult to offer detailed recommendations for these groups and further study in this area is needed. In addition, while senior level stakeholders were very willing to collaborate, it was challenging to find front-line staff to participate in interviews.

A main strength of the studies was the extensive involvement of the steering committee, which provided input into study design, instrument development, and report preparation to ensure appropriateness, relevance, and clarity. Their support for data collection was significant and all partner colleges participated in the interview process. The enthusiasm of senior level participants and their willingness to engage in interviews was of significant value.

Another strength of the studies was the "matching" of researchers whose experience related to specific target groups. Thus, a senior administrator interviewed senior administrators, a front-line staff member interviewed front-line staff, a new graduate worked with students, and so forth. This approach ensured study participants were comfortable exchanging knowledge with their peers.

\section{Recommendations and Next Steps}

Members of the steering committee worked with researchers to generate recommendations based on study findings. Discussions focused on how to best facilitate the implementation of the best practices and ensure that these practices are congruent with the needs of all students. Two key recommendations emerged.

First, there was a strong recommendation to find an effective mechanism for sharing best practices across the post-secondary system in Alberta. This needed to include not only a description of the best practices, but also a variety of tools and strategies that would assist college personnel in their implementation. 
The year following the research was dedicated to the development of an eToolkit that is currently hosted by eCampusAlberta. The eToolkit (Fiege \& Wilde, 2010) explores a range of student services and the evidence-based processes and characteristics that make them successful. It is organized according to 10 student support service categories, and summarizes findings from the literature and the two research studies in relation to each category. The eToolkit also presents policy considerations for each service category, provides samples of "successful practices" from existing institutions, and supplies flexible measures for organizations to assess their own policies and procedures $^{8}$.

The second recommendation emerged from a discussion of the best practices behind the best practices, where members of the steering committee agreed that without the backbone of policy, improvements in services for diverse distributed students would be inconsistent at best. The general absence of institutional policies related to distributed learning discovered in the policy review portion of these studies further indicated that this was an area in need of attention. This recommendation resulted in a development process where the partner institutions worked together to identify gaps in policy and to develop, with the assistance of a policy consultant, generic policies that could be adapted for their own use. In addition, five of the institutions worked with the consultant to create or adapt individualized policies related to distributed learning. A policy toolkit was subsequently developed to assist organizations seeking to be truly "bimodal" in providing the same high standards of service and support to distributed students as their on-campus counterparts (Wood, 2011). The toolkit outlines processes for developing comprehensive institutional policies in relation to distributed learning, including samples for reference ${ }^{9}$.

\section{Acknowledgements}

We would like to thank the anonymous reviewers for their constructive and helpful comments. These studies were funded by Alberta Ministry of Advanced Education and Technology (Successful Practices) and eCampusAlberta (Diverse Students).

\footnotetext{
${ }^{8}$ Interactive and print versions of the Student Services eToolkit can be accessed through the eCampusAlberta Web site (etoolkit.ecampusalberta.ca/).

${ }^{9}$ The Policy Development Toolkit is also available on the eCampusAlberta Web site (http://www.ecampusalberta.ca/files/Toolkit-Policy_Development.pdf).
} 


\section{References}

Allen, I. E., \& Seaman, J . (2009). Learning on demand: Online education in the United States, 2009. Retrieved from the Sloan Consortium Web site: http://sloanconsortium.org/publications/survey/learning_on_demand_sr $\underline{2010}$

Bates, T. (2011). 2011 Outlook for online learning and distance education. Sudbury, ON : Contact North. Retrieved from http:// provost.ncsu.edu/governance/ taskforces/distance-education/2011/documents/2011-outlook-for-online-learningand-de.pdf

Borokhovski, E., Bernard, R. M., Mills, E., Abrami, P. C., Wade, C.A., Tamim, R., Bethel, E., Lowerison, G., Pickup, D., \& Surkes, M. A. (2011). An extended systematic review of Canadian policy documents on e-Learning: What we're doing and not doing. Canadian J ournal of Learning and Technology, 37(3), 1-32.

Canadian Council on Learning (2009). State of e-learning in Canada. Retrieved from http:// www.ccl-cca.ca/pdfs/E-learning/ E-Learning_Report_FINAL-E.pdf

Contact North (2012). Online learning in Canada: At a tipping point - a cross-country check-up 2012. Retrieved from http:/ / www.contactnorth.ca/ sites/ default/ files/ pdf/innovationpractices/onlinelearningincanadareport_june_12_2012.pdf

Fiege, K. (2010). Successful practices in supporting students in distributed learning \& meeting the needs of diverse students engaging in e-learning: Literature review. Retrieved from eCampusAlberta Web site: http:// www.ecampusalberta.ca/ sites/default/files/pdf/Literature Review Report.pdf

Fiege, K., \&Wilde, R. (2011). Supporting students in distributed learning: An eToolkit. Retrieved from eCampusAlberta Web site: http:// etoolkit.ecampusalberta.ca/

Floyd, D. L., \& Casey-Powell, D. (2004, Winter). New roles for student support services in distance learning. New Directions for Community Colleges (pp. 55-64). Boca Raton, FL: Wiley Periodicals.

Goodman, L. (1961). Snowball sampling. Annals of Mathematical Statistics, 32, 148170.

LaPadula, M. (2003). A comprehensive look at online student support services for distance learners. American J ournal of Distance Education, 17(2). 119-128. doi: 10.1207/S15389286AJ DE1702_4 
McCracken, H. (2005). Web-based academic support services: Guidelines for extensibility. Online J ournal of Distance Learning Administration, 8(3). Retrieved from http:// www.westga.edu/ distance/ ojdla/ fall83/ mccracken83.htm

Moore, J . L., Dickson-Deane, C., \&Galyen, K. (2011). e-Learning, online learning, and distance learning environments: Are they the same? Internet and Higher Education, 14(2), 129-135. Retrieved from https:// scholar.vt.edu/access/ content/ group/ 5deb92b5-10f3-49db-adeb7294847f1ebc/e-Learning\%20Scott\%20Midkiff.pdf

Nagel, D. (2009, October). Most college students to take classes online by 2014. Campus Technology. Retrieved from http:// campustechnology.com/articles/2009/10/28/ most-collegestudents-to-take-classes-online-by-2014.aspx

Parker, K., Lenhart, A., \& Moore, K. (2011). The digital revolution and higher education: College presidents, public differ on value of onlinelearning. Retrieved from the Pew Research Center Web site: http:// www.pewinternet.org/ / media// Files/Reports/2011/PIP-OnlineLearning.pdf

Radford, A. W. (2008). Learning at a distance: Undergraduate enrollment in distance education courses and degree programs. Retrieved from the National Center for Education Statistics, US Department of Education Web site: http://nces.ed.gov/pubs2012/2012154.pdf

Shimoni, R., \& Barrington, G. (2010). Meeting the needs of diverse students engaging in e-Learning. Retrieved from the eCampusAlberta Web site: http:// www.ecampusalberta.ca/sites/default/files/pdf/PhaseII_DiverseLe arners FINAL_POLICY REPORT web.pdf

Shimoni, R., Barrington, G., \&Wilde, R. (2010). Successful practices in supporting students in distributed learning. Retrieved from the eCampusAlberta Web site: http:// www.ecampusalberta.ca/files/ FINAL\%20REPORT\%20Successful\% 20Practices.pdf

Wood, D. (2011). A policy development toolkit for online learning. Retrieved from the eCampusAlberta Web site: http:// www.ecampusalberta.ca/files/ ToolkitPolicy Development.pdf 


\section{Athabasca University}

(c) (7) 